\title{
ATTACK BEHAVIOR OF DIGUETID SPIDERS AND THE ORIGIN OF PREY WRAPPING IN SPIDERS ${ }^{1}$
}

\author{
By William EBerhard
}

\section{Biological Laboratories, Harvard University}

Spiders use silk in prey capture in two ways: in the construction of webs which trap and partially immobilize prey, and in wrapping prey. Aerial webs have evolved independently in several families of spiders, including the Araneidae, Uloboridae, and Diguetidae (Kaston, 1966). As pointed out by Savory (1952, p. 20), a spider's web greatly extends the area covered by its sense of touch; it also at least partially immobilizes any prey which encounters it. Thus a webliving spider is more likely to "encounter" a new, partially subdued prey while handling another than is a webless spider. Most prey which become caught in a web will eventually work free and escape unless they are further immobilized. Barrows (1915) found that flies remained in the orbs of Araneus sericatus (Epeira sclopetaria) an average of only 5 seconds. However, most aerial web spinning spiders hang upside down in their webs, and if they dropped a prey which they had already caught while making a new attack, it would fall from the web and be lost. It is probably for this reason that many of these spiders wrap their prey and secure it to the web soon after encountering it, thus freeing their chelicerae for subsequent attacks.

Araneids and uloborids spin orb webs and use silk extensively to immobilize prey. Diguetids spin less highly organized webs, and never use silk in prey immobilization. However, they often apply silk to prey already subdued by biting. This paper shows how postimmobilization prey wrapping may have led to the use of silk as an attack weapon by the orb weavers.

I observed the following species attacking prey: Aphonopelma sp. (Theraphosidae, various ages, both sexes), Metepeira labyrintha (Hentz) (Araneidae, various ages, both sexes), Argiope trifasciata (Forskal) (Araneidae, females of various ages), Uloborus diversus

\footnotetext{
${ }^{1}$ Research supported by a grant from the Committee on Evolutionary Biology at Harvard, publication by Public Health Service Research Grant AI-01944 to Dr. H. W. Levi. I wish to thank Mr. Frederick Shepard, Mrs. Lorna Levi, and Drs. M. J. West and F. M. Carpenter for help in preparing this paper. This work was done under the direction of Dr. H. W. Levi.
}

Manuscript received by the editor August 1, 1967 
(Marx) (Uloboridae, all ages, both sexes), Diguetia canities (McCook) (Diguetidae, mature females), and Linyphia marginata (Koch) (Linyphiidae, various ages, both sexes). While the behavior of spiders is often regarded as quite stereotyped, there was great variation in the details of attack sequences, even those exhibited by a single individual. However, the basic outlines of an attack were quite constant for the species observed, and, at least in one case, appear to be for an entire family (Uloboridae) (Marples, I962, 1966). I have attempted to describe only these relatively fixed aspects of their behavior. Unless otherwise noted, the descriptions apply to attacks in well-lit situations on live prey at least $\mathrm{I} / 3$ the size of the spider. Simpler attacks on smaller prey sometimes occur (especially in Araneidae).

Kaston ( I966) surmises that the earliest spiders had no silk, and relied on speed and agility to capture their prey. The webless theraphosids, in the Mygalomorpha which is morphologically a primitive sub-order of spiders, used little more than this in their attacks. As also observed by Baerg (1959) and Gertsch (1949), they attacked by holding the prey with the tarsi of the legs and pulling it close to the mouth where it was bitten with the powerful chelicerae. The prey was overcome and held by the spider's chelicerae until their crushing action and poison immobilized it. Very little if any silk was used in the attacks. Occasionally, however, with the partially subdued prey held in the chelicerae, the spider arched its cephalothorax away from the ground and turned slowly in a circle, dabbing its spinnerets to the ground periodically. Possibly the silk laid during these actions served to give the spider a better grip on the substrate.

The attack behavior of the araneids and uloborids differed from that of the theraphosids. They spun orb webs and responded to the struggles of prey trapped in the web by running to it and quickly swathing it in silk. Araneids generally held the radius (or radii) on which the prey was resting with both legs II, straddling the prey as they wrapped it. Legs IV alternated in pulling swathing silk from the spinnerets and looping it over the prey. The spiral strands in which the prey was entangled were broken, and the band of swathing silk was wrapped onto the prey as it was spun rotisserie fashion by the palps and legs III and I. The spider bit the prey briefly with its chelicerae soon after the swathing began, and then delivered a longer bite after the prey was more completely wrapped. After the prey was completely covered with silk, the spider freed it from the web and attached a short line to it. Holding this line 
in tarsus IV, it carried the prey back to the hub of the web (or to its retreat) where it often wrapped the prey further. Then, as it turned to its normal head-down position, it attached the line from the prey bundle to the threads at this site, and began to feed, holding the prey with the palps and probably the chelicerae. If another prey landed on the web, the first prey was dropped, and hung by the short

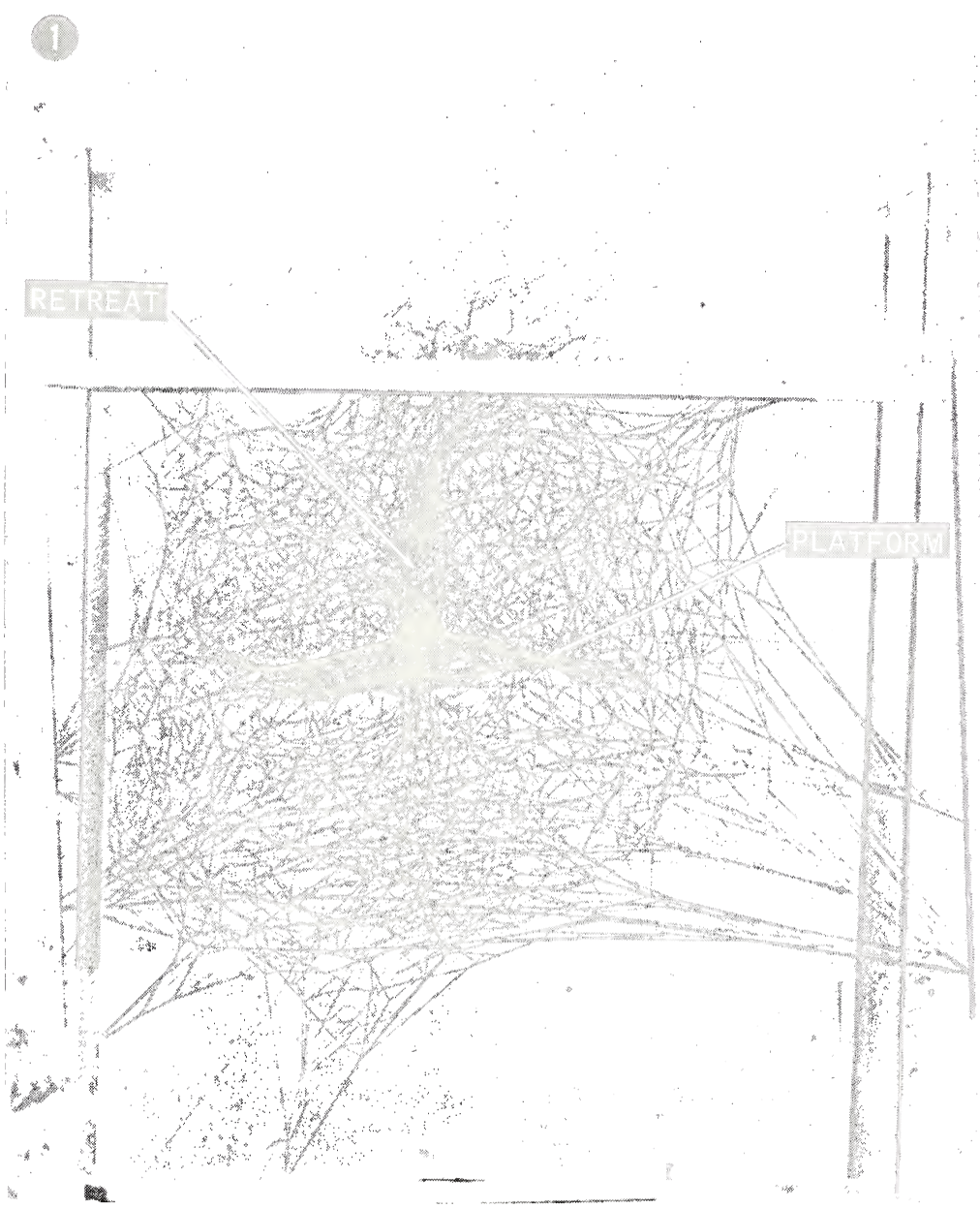

Figure 1. Web of mature female Diguetia albolineata built in a frame of wood and cardboard. 
line as the spider rushed off to attack. This description agrees in all major points with those of Savory (I950) and Peters ( I93 I, I933).

The attacks by uloborids that I observed and that Marples reported ( I962) were similar to those of the araneids with three major differences.

I. The prey was never bitten (Uloboridae have no poison glands). Immobilization was accomplished entirely by use of silk. This total reliance on silk represents the farthest departure of any spider from the primitive attack formula of "grasp and poison".

2. The prey was always carried in the palps and was never attached to the web. If another prey landed on the web the first was carried to the attack site, and often the two were wrapped into a single bundle. The presence of the first prey did not seem to hinder the movements of the second attack in any way.

3. Rather than straddling the prey at the start of an attack, the spider often turned to face away from it and pulled silk from the spinnerets, guiding it toward the prey with legs IV. In general, the larger the prey was, the farther the spider stayed from it as it commenced wrapping. The uloborids were thus farther from the struggling prey than the araneids in the initial stages of attack when the prey was least subdued.

The observations reported so far suggest this situation: primitive - capturing prey with legs and chelicerae, holding it with the chelicerae and using poison to subdue it, not applying silk to it; advanced - capturing and subduing prey from a distance by applying silk to it, holding it with appendages other than the chelicerdt.

A clue to the origin of the use of silk in the evolution of attack behavior comes from the behavior of spiders in the poorly known family Diguetidae. These spiders spun relatively organized webs that were somewhat similar to those spun by linyphiids. The web was a roughly circular mesh platform suspended in a network of more widely spaced supporting strands. A nearly cylindrical "retreat" hung in the mesh just above the center of the platform (Fig. I). The undersurface of the platform was continuous with the inside of the retreat. The spider remained inside the retreat during the day, and hung under the platform near the retreat at night.

When a prey fell onto the platform, the spider rushed out from 
the retreat and grappled with it. ${ }^{2}$ If the prey was active (a moth for example), there was often a struggle lasting several seconds before the spider was able to grip it securely with the chelicerae, and the prey often escaped at this stage. Legs I were commonly thrust through the platform and their tarsi brought down on top of the prey, pressing it firmly against the platform and bringing it close to the chelicerae.

Biting and poisoning behavior was usually released only if the prey struggled. Only underfed spiders bit immobile prey. When a recently killed cockroach was dropped onto the platform, the spider rushed to it and grabbed it with legs I (and II?), but did not bite it. When the roach was pulled gently with forceps, the spider bit it. Objects which did not move within about 5 minutes of contact were pulled through the platform (see below) and dropped. Deathfeigning insects may thus sometimes avoid capture.

Once the spider had a good grip with the chelicerae it held on until the prey's struggles subsided (usually about Io minutes after the attack for prey about $\mathrm{I} / 2$ the spider's size). If the prey was strong it sometimes pulled the spider around a bit before the poison took effect. All eight of the spider's legs were used to maintain its grip on the platform when this happened.

About five to ten minutes after the attack the spider slowly disengaged the prey (usually still twitching) from the web, pulling it through a slit in the platform made by breaking some strands and pushing others aside. Lines were cut by bringing them to the mouth region with tarsi III (and II?). Once when the prey was quite large in relation to the spider, the spider attached a line to the platform threads and then fixed this line to the prey before releasing its hold with the chelicerae to begin removing the prey from the web. This line anchored the prey more securely as the disengagement process began.

Often, especially when it was large, the prey got stuck as it came through the platform, and the spider tugged and pulled at it until it came free. Most, if not all, movements involved in freeing the prey from the web were accompanied by movements of the abdomen

${ }^{2}$ If the prey was entangled in the lines above the platform, the spider shook the web violently several times, sometimes causing the prey to fall onto the platform. If the prey did not fall, the spider sometimes climbed into the mesh to attack it there. The holes in the platform near the mouth of the retreat were occasionally used to gain access to the upper mesh, as Cazier and Mortenson (1962) supposed. Other times the spider climbed around the outer edge of the platform and into the upper mesh. 
that caused the spider and the prey to bounce under the platform an estimated 5-IO times/sec as if it were an inverted trampoline. The function of these bouncing movements is not clear.

Holding the freed prey in its chelicerae, the spider carried it to the retreat, entered the mouth of the retreat, turned $\mathrm{I} 80^{\circ}$, and began to eat facing downward. If another victim fell onto the platform the spider's first reaction was often to attach a line to the platform near the retreat. It then attached this line to the prey being eaten, and slowly rotated the prey so that several loops of thread were placed around it (almost everything diguetids do associated with spinning is quite slow and clumsy when compared with the orb
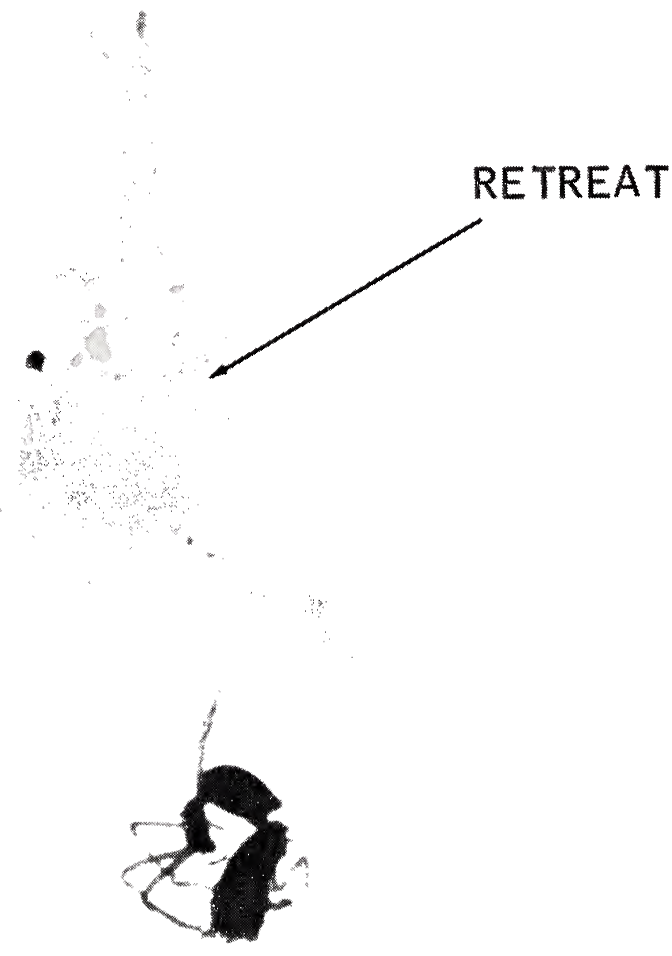

Figure 2. Mature female Diguetia albolineata wrapping a cockroach. 
weavers' actions). 'The line was then attached to the prey and the platform again, and the spider left the prey dangling there as it rushed off to the second attack. Wrapping behavior often occurred just after the spider returned from an attack even in the absence of a second prey.

The actions involved in wrapping the prey were invariable, and to my knowledge, unique to the Diguetidae. The spider lowered itself until just the extended legs IV were holding the platform. With its abdomen bent at about $90^{\circ}$ to its cephalothorax, the spider took the prey from its chelicerae and pressed it to its spinnerets with legs I, II, and III. It made one or more attachments to the prey, then rotated it slowly with these legs and laid a line around it. Additional attachments were sometimes made as the prey was turned. The number of turns was roughly dependent on the size of the prey and was usually between two and ten. Fig. 2 shows a Diguetia albolineata in the wrapping posture.

The aggressive use of silk by araneids and uloborids may be an elaboration of behavior like that of the diguetids. In the diguetids wrapping served only to anchor an already immobilized prey, whereas it was one of the chief means of immobilization for the orb weavers. The change from post-immobilization wrapping like that of the diguetids to uloborid-like immobilization wrapping would involve I. wrapping at the site of capture, 2. wrapping the prey before it was immobilized by poison, and 3. applying greater quantities of silk to the prey. None of these steps involves elaborate behavior patterns not shown by the diguetids, and in fact under some conditions (large, strong prey) they will perform step $\mathrm{I}$.

The behavior of spiders in the family Linyphiidae gives another indication that the change from post immobilization to immobilization wrapping can occur easily. The linyphiids are allies of the Araneidae with web spinning and prey wrapping habits similar to those of the Diguetidae. They often applied a number of loops of silk to prey after it had been bitten, pulled through the web platform, and carried back to the center of the web. Their behavior differed from that of the diguetids in that they wrapped the prey much more often at the site of capture (always after biting it), and laid a longer line of silk onto the prey. Also, wrapping behavior was not as consistently released by the presence of another prey on the web. The first two differences indicate that silk is more of an offensive weapon for these linyphiids than for the diguetids. However, they apply less silk, and use it later in the attack sequence than 
the araneids, so their attack behavior is intermediate between that of the diguetids and that of the araneids.

The family Diguetidae is probably far from the evolutionary lines leading to the Araneidae and Uloboridae, but it is almost certain that some of the same selection pressures acted on animals in all of these lines as they became adapted to life in aerial webs. Thus it seems reasonable to suggest that the evolution of wrapping behavior in the orb weavers may have included steps similar to the behavior of the diguetids. This is not certain, however, as I have observed some spiders [Hersalia sp. (Hersiliidae), Filistata arizonicus (Filistatidae), and Oecobius sp. (Oecobiidae)] which perform immobilization wrapping and which live on (or near) the ground. The ancestors of the araneids and/or the uloborids may have had the ability to wrap prey even before they began to build aerial webs.

In summary, the steps from post immobilization wrapping to immobilization wrapping are not large, and intermediate behavior can be found. The elicitation of wrapping in diguetids by the presence of new prey in the web suggests that wrapping may have originated as a post-immobilization process designed to free the spider for new attacks, and only later devolved into a means of attack.

The possible stages of evolution of attack behavior, coupled with stages of web evolution (Kaston, 1966), are summarized below.

I. Prey is overcome by holding and biting, no trapping web is spun (Theraphosidae, Clubionidae, Salticidae, many others)

2. Low-lying trapping webs are built, prey are subdued by holding and biting (Agelenidae, Plectreuridae)

3. Aerial trapping webs are built, prey are overcome by holding and biting and are wrapped to prevent their loss during subsequent attacks (Diguetidae, Linyphiidae)

4. Aerial trapping webs are built, prey are overcome by biting and wrapping (Araneidae, Theridiidae)

5. Same as 4 except prey are overcome exclusively by wrapping (Uloboridae)

\section{REFERENCES}

BaERG, William J.

1958. The Tarantula, Univ. of Kansas Press, Lawrence, p. 15.

BARRows, W. M.

1915. The reactions of an orb-weaving spider, Epeira sclopetaria Clerk, to rhythmic vibrations of its web, Biol. Bull. 29:316-32. 
Cazier, M.A., and M. A. Mortenson

1962. Analysis of the habitat, web design, cocoon and egg sacs of the tube weaving spider Diguetia canities (McCook), Bull. So. California Acad. Sci. 61(2): 65-88.

GERTSCH, WILLIS

1949. American Spiders, D. van Nostrand Co., New York, p. 123-26.

1958. The spider family Diguetidae, Am. Mus. Novitates, no. 1904: 1-24. Kaston, B. J.

1966. Evolution of the web, Natural History 75(4): 27-32.

MARPles, B. J.

1962. Notes on spiders of the family Uloboridae, Ann. Zool. Agra (India) 4(1): 1-11.

1966. personal communication.

MELCHERS, M.

1967. Der Beutefang von Cupiennius salci (Keyserling) (Ctenidae), Z. Morph. Okol. Tiere 58: 321-46.

Peters, $\mathrm{H}$.

1931. Die Fanghandlung der Kreuzspinne, Z. Vergl. Physiol. 15: 693748.

1933. Weitere Untersuchengen uber die Fanghandlung der Kreuzspinne,

SAVORY, T. H.

Z. Vergl. Physiol. 19: 47-67.

1952. The Spider's Web, Frederick Warne \& Co., New York, p. 127-32. 


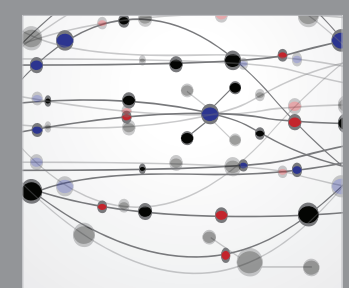

The Scientific World Journal
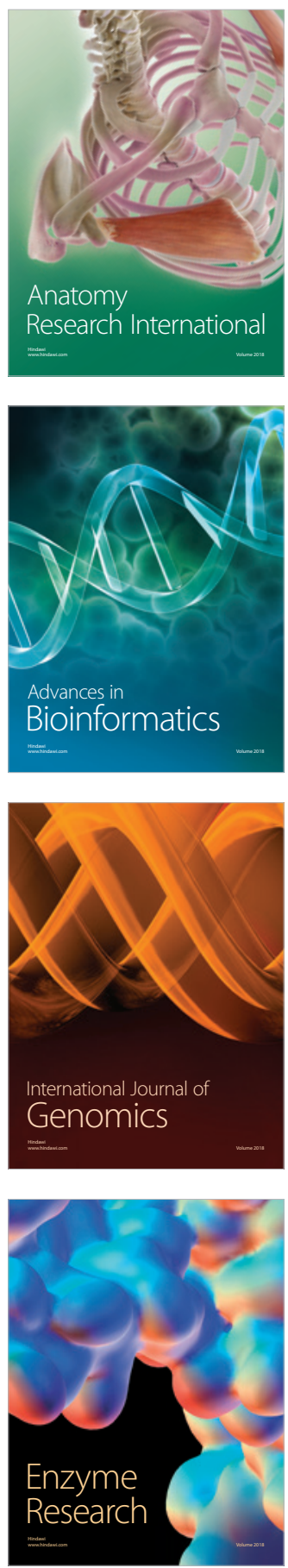
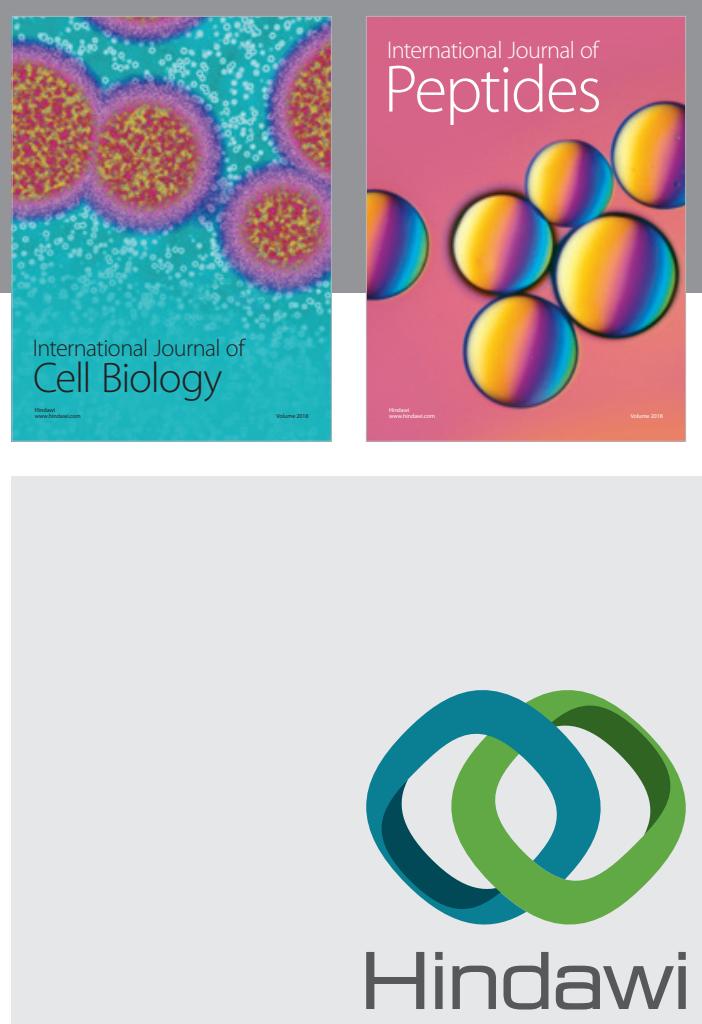

Submit your manuscripts at

www.hindawi.com
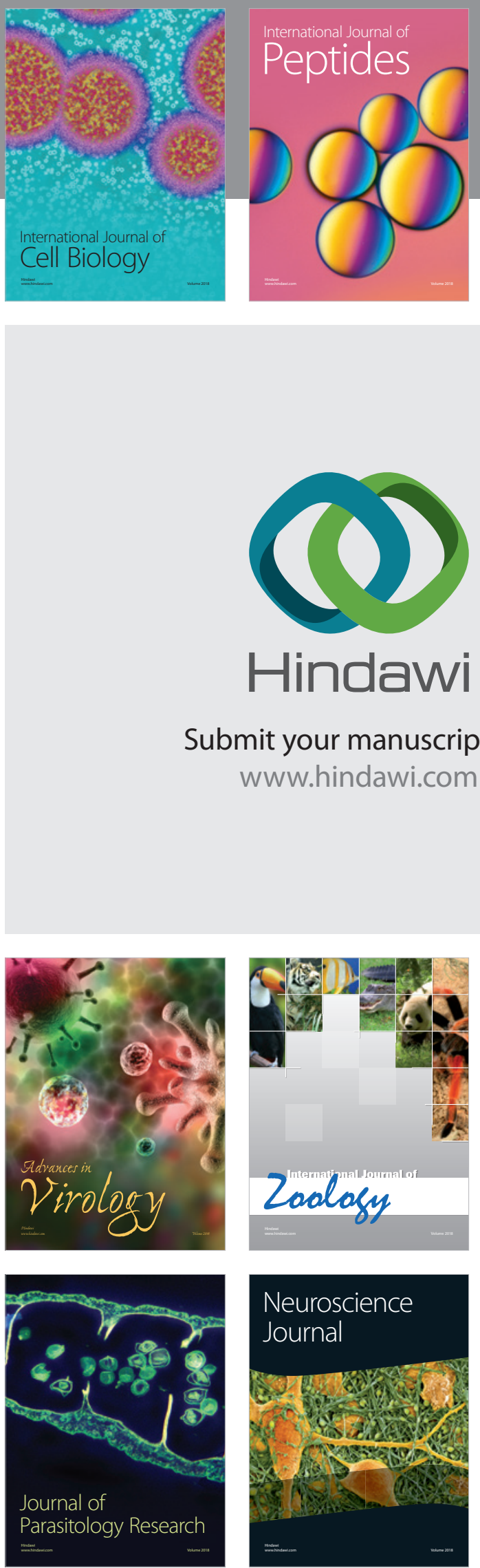
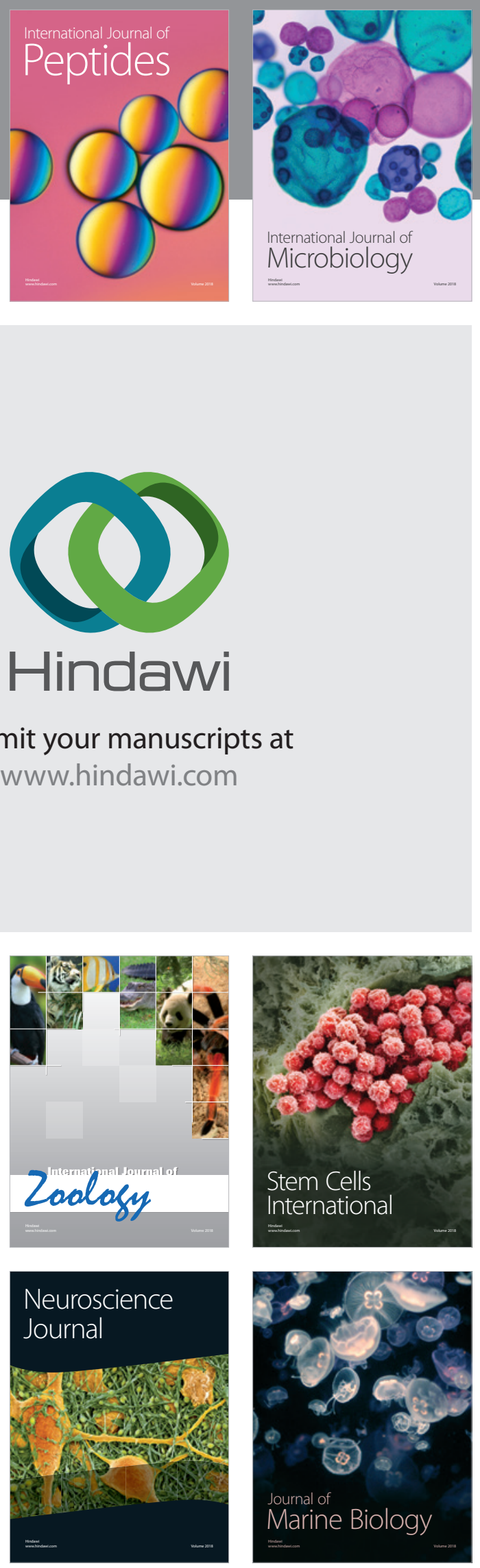
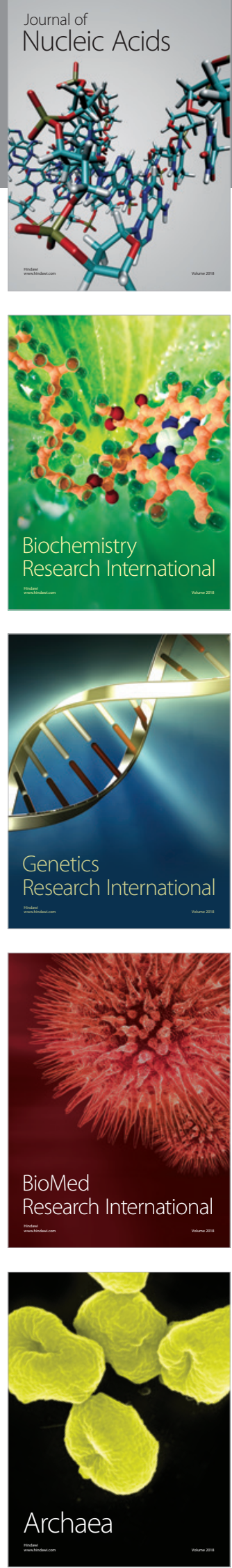